\title{
ローカルマップ統合によるユーザとモノの屋内位置推定
}

\section{Simultaneous Position Estimation of both User and Object in Indoor Environment based on Integrating Local Maps}

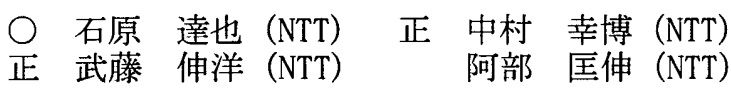

\author{
Tatsuya ISHIHARA, NTT, ishihara.tatsuya@lab.ntt.co.jp \\ Yukihiro NAKAMURA, NTT \\ Shin-yo MUTO, NTT \\ Masanobu ABE, NTT
}

\begin{abstract}
We propose a new method that can simultaneously estimate the positions of both user and sensors attached to objects in indoor environments. The position estimation of them is achieved by hierarchically structuring local positioning and global positioning. In local positioning, local maps are automatically generated and updated continuously, in addition to estimating the user position simultaneously by utilizing the suitably selected log data for improving the accuracy of position estimation according to a reliability factor in the user model combined with SLAM. In global positioning, the global map is automatically generated by integrating local maps, focusing on the common sensors which exist on two or more local maps and the distances (which are weighted by likelihood on the local map) between sensors. Advantages of the proposed method are (1) calibration free, (2) dynamic extension of covered area. Evaluation results show that estimation errors were less than $400 \mathrm{~mm}$ in both user and sensors positions, and small enough to develop context-aware indoor service taking into account the personal space.
\end{abstract}

Key Words: Position estimation, Auto-calibration, SLAM

\section{1. はじめに}

近年, ネットワークの高度化ならびにセンサなどのデバイ スの小型化に伴い, ユビキタスコンピューティングやウェア ラブルコンピューティングを用いたサービスが現尖味を带び てきた.これら技術を利用して，ユーザの周辺にある家具や 机, ソファーといったモノの空間配置とその空間内でのユー ザ位置を取得することができれば，様々な用途への展開が期 待できる. たとえば, ユーザがテレビ周辺のソファーにいる とシステムが判断した場合には，ユーザが携带する端末にテ レビの操作パネルを提示するといった, ユーザの状沈に応じ たサービスが期待される.このようなサービスを実現するた めには, 1.2m程度のいわゆるパーソナルスペース[1]を識別で きる精度で位置を推定することが求められると考えられる.

屋外であれば GPS を利用することによりユーザやその周辺 の建物などの位置を取得することができる.…方, 屋内での ユーザやその周辺のモノの位置をセンシングするシステムは まだ実用に至っていない.

我々はこれまでに, ユーザ周辺の家具, 机, イスなどのモ ノにセンサを取り付け，それらセンサとの相対距離を計測で きる計測端末をユーザが携带し，ユーザの移動とともに逐次 計測される相対距離情報を用いることでユーザ周辺のモノの 空間配置とユーザの位置を推定する手法を提案し, 性能評価 を行ってきた[2]. しかしながら，この手法では，予め定めた 代表となるセンサ（代表センサ）が計測端末と常に距離計測 を行う必要があった。 そのため，これらセンサの計測レンジ を外れるような環境での適用が困難であった，そこで，本稿 では，通信端末が同時刻に距離計測を行ったセンサ集合に代 表センサが存在しない場合には，それらセンサ集合の中から 新たに代表センサを定め, 新規にモノの空間配置（ローカル マップと呼ぶ）を逐次生成し，それらマップを統合すること で全体的なモノの空間配置（グローバルマップと呼ぶ）とそ の空間中でのユーザの位置を推定する手法を提案する．また， 提案手法の実環境における性能評㑋結果について報告する. この手法によって, センサの設置箇所を考慮することなく,
設置するセンサの厳密な位置合わせやセンサセットアップに 必要なキャリブレーションが不要となるため, 屋内でのユー ザやモノの位置センシングのための導入コストを抑えながら， さまざまなサービスへの展開が期待できる.

\section{2. ロ一カルマップの統合}

本研究では, ID を付与された複数のセンサを生活環境中の $\mathrm{TV}$, 机等の任意のモノに分散配置する. そして, それらセン サと通信して相対距離を計測する計測端末をユーザが携带し， 日常生活においてユーザが空間中を移動することを利用して， その環境における計測端末とセンサの位置を同時に推定する 手法を提案する. 以降, モノとユーザをそれぞれセンサと計 測端末に対応付ける.

このような環境におけるユーザとモノの位置推定を 2 つの ステップにより実現する. Step1) センサセットアップの低減 化を図るべく, 環境中におけるランドマーク位置とロボット 位置の同時位置推定を実現できるロボット工学における SLAM [3]に着目し, 逐次変化する代表七ンサの組合せに応じた ローカルマップの生成と計測端末の位置推定ならびにそれら 推定位㯰の尤度を算出する. Step2) 逐次形成される各ローカ ルマップに共通して存在するセンサと, ローカルマップにお ける各センサ推定位置の尤度により新たに定義される信頼度 によって重み付けされたセンサ間距離に着目してグローバル マップの作成を行う。ついで, グローバルマップの情報を用 いて計测端末位置の算出を行う。以降, Step. 1)とStep. 2) の 処理をそれぞれローカルポジショニング[2], グローバルポジ ショニングと呼ぶ.

\section{3. 定式化}

本節では，グローバルポジショニングを定式化する．グロ 一バルポジショニングでは, 通信端末が同時刻に距離計測を 行った代表センサの組み合わせ毎に生成された複数のローカ ルマップ間に共通して存在するセンサに着目し，これらロー 
カルマップを 1 つのローカルマップ（以降，基準マップと呼 ぶ）に設定された座標系上に統合することでグローバルマッ プの生成を行う。ついで, グローバルマップの情報をもとに 計測端末の位置推定を行う。以降, 説明のため, ローカルマ ップ $\Sigma_{o}$ を基準マップとする.

\section{1 ローカルマップの統合判定}

二次元平面の場合, 異なるローカルマップに 3 個以上の共 通センサが存在すればそれらセンサを利用して 1 つのマップ に統合することができる，この点に着目して，統合可能な口 一カルマップの組み合わせを探索し, 基準マップに対する各 ローカルマップの結合関係を抽出する. 具体的には, 各ロー カルマップが基準マップと統合する際に経由寸る最小のロー カルマップの数（ホップ数と呼ぶ）を算出する（図 1).

\section{2 信頼度を用いたセンサ間加重平均距離}

ローカルポジショニングにおいて算出された各センサ推定 位置から各ローカルマップにおけるセンサ間距離の算出を行 う.ついで, 算出されたセンサ間距離を用いてグローバルマ ップにおけるセンサ閣の距離推定を行う。

複数のローカルマップにおいて同一のセンサの組合せがあ る場合, それらローカルマップ上で算出されたセンサ間距離 は各ローカルマップによって異なる. そこで, 各ローカルマ ップで算出されたセンサ間距離の信頼度を新たに定義し, そ の信頼度を用いた加重平均を用いてグローバルマップにおけ るセンサ間距離を算出する。これにより，センサ間距離が 意に求まるだけでなく，ローカルマップ上で算出された信頼 度の低いセンサ間距離の影響を低減させることが可能となる。 センサ間距離の信頼度は, 距離算出に用いた 2 つのセンサ推 定位置の精度を考慮するため, ローカルポジショニングによ り算出されたこれら推定位置の尤度の積で表現する。

例えば, $\mathrm{S}_{\mathrm{ij}}$ をセンサ $\mathrm{i}$ とセンサ $\mathrm{j}$ を含むローカルマップの集 合とし, ${ }^{k} L_{i j},{ }^{k} w_{i j}$ をそれぞれローカルマップ $\Sigma_{k}$ 上で算出され たセンサ i-j間の距離とその信頼度とした場合，グローバルマ ップ上でのセンサ $\mathrm{i}-\mathrm{j}$ 問の距離动

$$
\overline{L i j}=\frac{\sum_{k \in S_{i j}}{ }^{k} w_{i j}{ }^{k} L_{i j}}{\sum_{k \in S_{i j}}{ }^{k} w_{i j}}
$$

\section{3 基㔼マップにおけるセンサと計䁌端末の位策推定}

センサ間の加重平均距離を用いてグローバルマップにおけ る各センサ位置を算出する. その場合，1)尒体の位置推定誤差 が最小になるように位置算出を行う方式と, 2)原点に近いセン サから順次位置を確定させていく方式が考えられる.1)の方式 では，誤差が均一になるように各センサ位置を算出すること ができる．...方，2)の方式では, 順次位置を確定させていくた め, 位置推定を行うごとにそれまでに算出されたセンサ位置 の推定誤差が重畳するが，原点に近いセンサほど位置推定の 誤差を抑えることができる(図1).

我々は，ユーザの状沉に応じたサービスにおいては，ユー ザ周辺のモノの空問配置が特に重要であると考える.そこで, グローバルマップ生成において，ユーザがいるローカルマッ プを基準マップと設定し，基準マップと結合関係が明らかに なったローカルマップに対してホップ数の昇順に順次統合す る. 具体的には, ホップ数の小さいローカルマップ上に存在 するセンサから順に式(3.2)を用いてセンサ $i$ の位置修正量

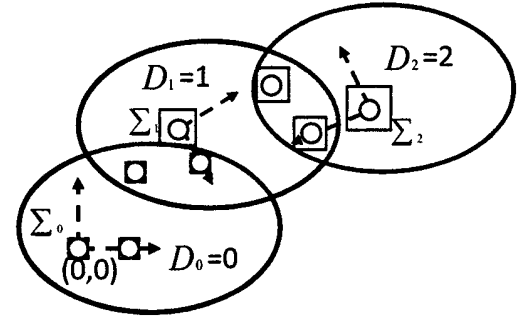

$\sum_{x}:$ Local $\operatorname{map} \mathrm{X}(\mathrm{X}=0,1,2)$

$D x$ : Number of hops of local map $\mathrm{X}(\mathrm{X}=0,1,2)$ from standard map

0 : Sensor position

$\square$ : Existing region of sensor

Fig.1 Integrating local maps

$\Delta x i$ を算出し, センサ $i$ の位置を更新する. ついで, $G$ に属 する全センサの位置修正量を算出するごとに式(3.3)の評価值 を算出する.ここで, $i, x i, g i, G, N$ はそれぞれセン サID, センサ $i$ の二次元座標值, センサ $i$ と同一のローカルマ ップ上に存在するセンサの中で既に位置算出が行われたセン サIDの集合, 基準マップと統合可能なローカルマップ上に存 在するセンサIDの集合， $G$ の要素数である.このとき, 式(3.2) が予め定めた閾值よりも大きい場合は, 再度式(3.2)を用いて順 次センサ位置の修正を行う。これにより，ユーザ周辺のモ， の空間配置の精度を高めながらも, 全体のセンサ推定位置の 誤差を抑えることができる。

$$
\begin{aligned}
& \Delta x i=\sum_{j \in g i} \frac{x i-x j}{|x i-x j|}\{L i j-|x i-x j|\} \\
& J=\sum_{i=0}^{N-1} \sum_{j \in g_{i}}\{|x i-x j|-\bar{L} i j\}^{2}, i, j \in G
\end{aligned}
$$

計測端末位置(xu,yu)に関しては, 基準マップ上にマッピング されたセンサ推定位.圆(xi,yi)とセンサ計测值di(t)から式(3.4)を 解くことで算出する.ただし，Uは計测端末が計測したセンサ IDの集合である.

$$
\begin{aligned}
& \mathrm{d}_{\mathrm{i}}(t)^{2}=\left(\mathrm{x}_{\mathrm{i}}-x_{\mathrm{u}}(\mathrm{t})\right)^{2}+\left(\mathrm{y}_{\mathrm{i}}-\mathrm{y}_{\mathrm{u}}(\mathrm{t})\right)^{2} \\
& i \in U
\end{aligned}
$$

\section{4. 実験}

実環境におけるグローバルポジショニング手法の性能評価 を行うべく，超音波センサを用いた笑験を行った.

\section{1 目的と条件}

環境中の机などの任意のモノに設置した超音波タグとユー ザが所持した超音波受信機の位置推定を行った. 実験環境図 と超音波タグ設置条件ならびに実験条件をそれぞれ図 2, 図 3, 表 1 に示す. 㝬験では古河機械金属（株）[4]製の超音波受信 機（ZPS-MK）をカートの先端に取り付け，超音波タグが物に 取り付けられた環境内でユーザがカートをランダムに移動さ せた. なお, 超音波受信機と各超音波タグ位置の参照位置は 3 次元位置の推定誤差が $30 \mathrm{~mm}$ 程度である本実験とは別の超音波 センサシステム（ZPS-3D）を用いて計測した（図 2).

\section{2 実験結果と考察}

\subsection{1 利用可能なエリアの执張性}

各ローカルマップ上で算出されたタグ ID とホップ数を表 2 に示寸. ニーザがカートを移動させることにより 27 個のロー 
カルマップが生成された. そのうち，10 個のローカルマップ 上でタグの位置算出が行われた。

本手法では，ユーザの移動範囲が狭いことに起因して増加 する位置推定誤差の影響[2]を回避するため，ローカルポジシ ヨニングにおいてログデータ選択の評価值に闘值を設定して いる，位置算出が行われなかったローカルマップが生じたの は，コーザの移動範囲が狭かったことで閥值を満たす距離デ 一タを取得することができなかったことに起因する.

また，グローバルマップに統合されたローカルマップ数と タグ数の時間経過を図 4 に示す. グローバルマップに統合さ れるローカルマップとタグの数が，時間経過にともなって増 加していることがわかる．これらから，代表センサ（タグ） が異なる場合においても，共通するタグに着目して複数の口 一カルマップを統合することで，各タグの位置推定範囲を拡 張できる見通しを得た。

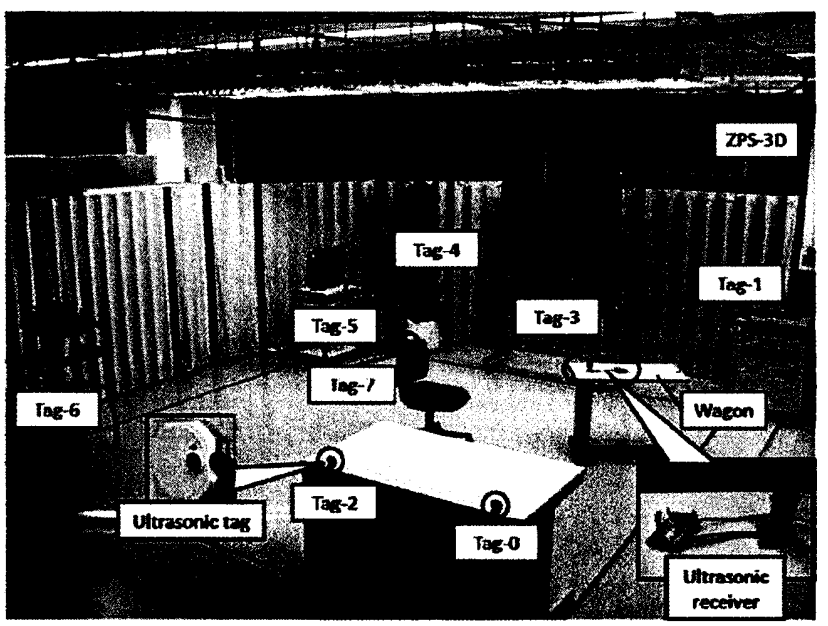

Fig.2 Experimental environment

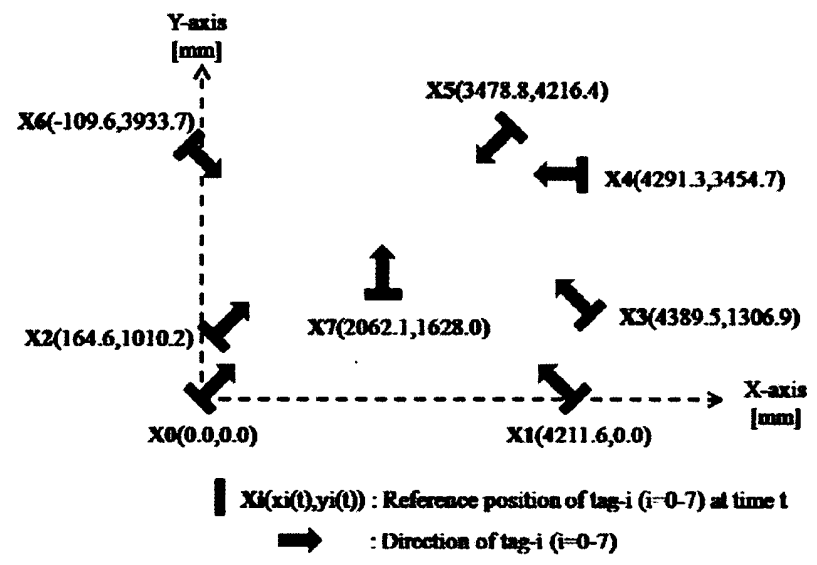

Fig.3 Location of tags in experiment

Table 1 Experimental conditions

\begin{tabular}{|c|l|}
\hline Receiver & $\begin{array}{l}\cdot \text { Movement region: inside of arrangement sensors } \\
\cdot \text { Receiving range: } 190 \mathrm{deg}\end{array}$ \\
\hline Tag & $\bullet$ Transmission range: $190 \mathrm{deg}$ \\
\hline Other & $\begin{array}{l}\bullet \text { Standard map: } 0 \text {-th local map } \\
\cdot \text { Sampling rate: } 1 \mathrm{~s}\end{array}$ \\
\hline
\end{tabular}

\subsection{2 位目推定精度}

1 ）超音波タグの推定誤差

グローバルポジショニングにより算出されたタグの位置推 定精度を確認するために，ローカルマップ $\Sigma_{o}$ を基準マップと 設定し，基準マップ上におけるタグの参照位置と推定位置間 の距離を推定誤差として評価した．時間経過に伴う各タグの 位置推定誤差の結果を図 5, 図 6 に示す. 時間の経過に伴い, センサの誤差が全体的に収束していることが分かる。一方， タグ 6 （図 6) については, 誤差が 500s 付近で一洔的に増加 している現象が見られた。詳細に分析した結果，タグ 6 の位 置算出を行ったローカルマップは $3 ， 15 ， 23$ であった。これ らマップがグローバルマップに統合されたタイミングにおけ る, 各ローカルマップでのタグ 6 の推定誤差結果を表 3 に示 寸.これから，タグ 6 の推定誤差の一時的な増加は，ローカ ルマップ 15 で推定された位置誤差の大きいタグ 6 の位置情報 がグローバルマップに写像されたためと考えられる．提案し たグローバルポジショニングでは各センサ位置の尤度の加重 平均を利用しているため, 過度な位置誤差が生じていないが, 今後, 改善しなければならないと考える.

つぎに，各センサ位置が収束した状態と見られる時刻 $529 \mathrm{~s}$ における各センサ位置推定誤差の結果を表 4 に示す. 表 4 よ り時刻 $529 \mathrm{~s}$ における各タグ位置の平均推定誤差は平均 $311.7 \mathrm{~mm}$ であり, パーソナルスペースを識別できる精度で位 置を推定できる見通しを得た。一方，表 4 から夕グ $4,5,6$ の位置誤差は，タグ $0 ， 1 ， 2 ， 3 ， 7$ のそれに比べて大きくな った. 誤差の要因として，1）ローカルポジショニングで推

Table 2 Tag ID on each local map and number of hops of each local map

\begin{tabular}{|c|r|r|}
\hline Local map ID & \multicolumn{1}{|c|}{ Tag ID } & Number of hops \\
\hline 0 & $0,1,2,3,4,7$ & 0 \\
\hline 2 & $0,1,3,4$ & 1 \\
\hline 3 & $1,3,4,5,6$ & 1 \\
\hline 4 & $1,4,5$ & 2 \\
\hline 5 & $2,4,5$ & 2 \\
\hline 6 & $1,2,3,7$ & 1 \\
\hline 12 & $3,4,5$ & 2 \\
\hline 15 & $4,5,6,3$ & 2 \\
\hline 18 & $0,2,3,4,5$ & 1 \\
\hline 23 & $3,4,6$ & 2 \\
\hline
\end{tabular}

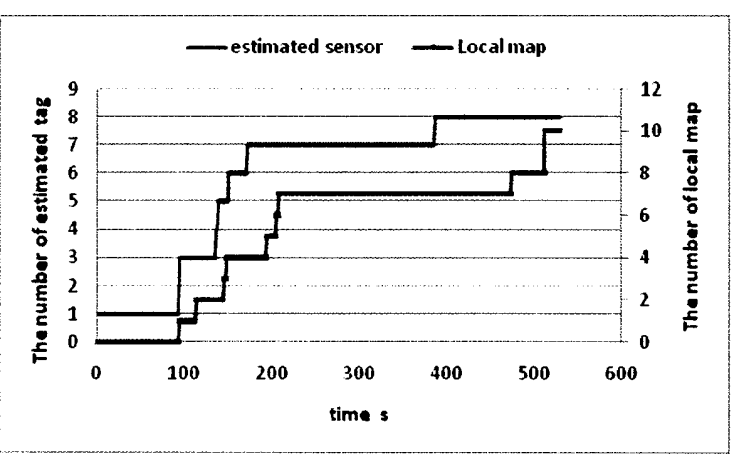

Fig.4 The number of local maps and estimated tags on global map 
定されたセンサの推定誤差，2）グローバルポジショニング で推定されたセンサの推定誤差が考えられる．提案している ローカルポジショニングでは，ユーザが環境内を動き回り， さまざまな場所で計測されたセンサと計測端末間の距離を利 用して位置を推定している，それゆえ，広範䎴な場所で得ら れた距離データを利用できれば，推定精度の向上が見込める と考える，逆に，狭い範囲の場所で得られた距離データしか 利用できない場合には，推定されたセンサの推定誤差が必然 的に大きくなると考えられる。 また，提案しているグローバ ルポジショニングでは，基準マップからのホップ数が小さい ローカルマップ上のセンサ位置から順次推定し，新たに推定 するセンサの位置は，それまでに推定されたセンサの位置を 基準に算出している，それゆえ，基準マップからのホップ数 が大きいローカルマップ上のセンサ推定位置は必然的に基準 としたセンサの位置誤差が蓄積される．タグ 4，5，6 の位置 誤差が他のタグの位置誤差に比べて大きい原因はこれらが唻 因と考えられるが, 今後, さらなる誤差の要因分析が必要と 考える.

2 ）超音波受信機の推定誤差

提案した手法による受信機の位置推定を評価するために, 尖験中の基準マップ上における受信機の参照位置と推定位置 の問の誤差を調べた.時間経過に伴う受信機の推定誤差を図 7 に示す. 図 7 より, 時間経過に伴って推定誤差が小さくなる 傾向が見られる．提案しているグローバルポジショニングで は，グローバルマップ上で位置が確定したセンサの中で，工 一ザを計測したすべてのセンサとユーザ問の距離を利用して ユーザの位置を算出する．それゆえ，時問経過に伴ってユー ザ位置算出に利用可能なセンサの数が増加し, 結果としてュ 一ザの位置推定誤差が小さくなったと考えられる．また，受 信機位置の推定誤差は平均 $375.6 \mathrm{~mm}$ であり, パーソナルスペ 一スを識別できる精度で位置を推定できる見通しを得た。

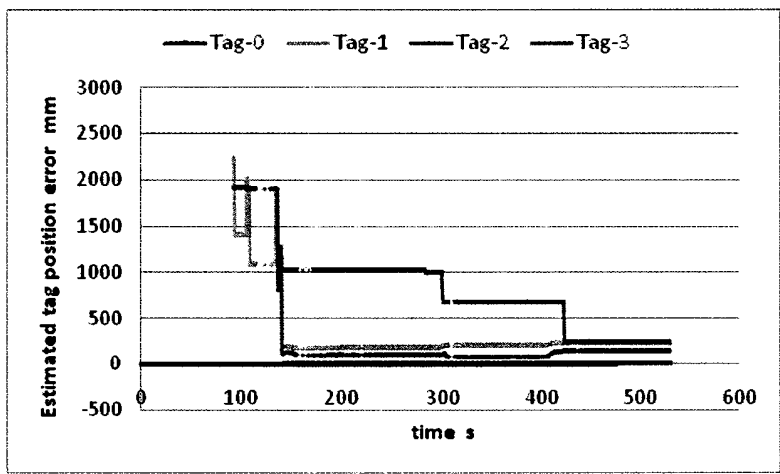

Fig.5 Estimated position tag-i $(\mathrm{i}=0-3)$ error

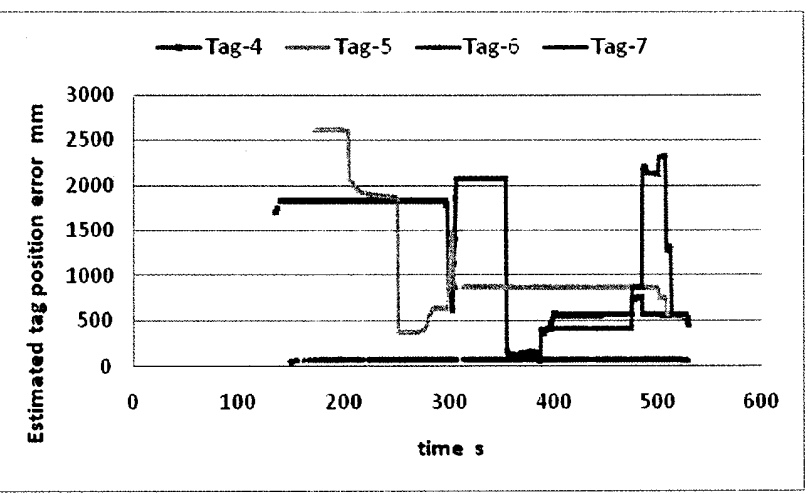

Fig.6 Estimated position tag-i $(\mathrm{i}=4-7)$ error

\section{5. まとめと今後の課題}

本研究では，代表センサの組み合わせ毎に生成される各口 一カルマップ上に共通して存在するモノに着目してそれらマ ップを統合し，全体的なモノの空問配置（グローバルマップ と呼ぶ）とその空間中でのユーザの位置を推定する手法を提 案した．ついで，超音波センサを用いた実験により提案手法 の性能評価を行い，パーソナルスペースを識別できる精度で 位置を推定できる見通しを得た。

今後はユーザが計测端末を所持した環境においても適応可 能なシステムの検討ならびに提案手法を用いたサービスの検 討を行う。

\section{文 献}

[1] E.Hall, :The Hidden Dimension, Anchor Books, 1990

[2]石原達也，中村幸博，武藤伸洋，阿部匡伸，下倉健一朗，"SLAM を用いたユーザやモノの间時位管推定", ロボティクスメカトロ 二クス講演会, 2A1-C10, 2009.

[3] S.Thrun, W.Burgard, and D.Fox, :Probabilistic ROBOTICS, The MIT Press, 2005.

[4] http://www.furukawakk.jp/

Table 3 Estimated tag- 6 position error when each local map was integrated with global map

\begin{tabular}{|c|r|r|r|}
\hline & $\begin{array}{c}\text { Time each map } \\
\text { was integrated s }\end{array}$ & $\begin{array}{c}\text { Estimated } \\
\text { position error } \mathrm{mm}\end{array}$ & \multicolumn{1}{|c|}{ Likelihood } \\
\hline Local coordinate 3 & 148 & 200.0 & 0.34 \\
\hline Local coordinate 15 & 475 & 3910.0 & 0.31 \\
\hline Local coordinate 23 & 513 & 220.0 & 0.35 \\
\hline
\end{tabular}

Table 4 Estimated position error

\begin{tabular}{|c|c|r|}
\hline \multirow{2}{*}{ Terminal } & Mean error & 375.6 \\
& Standard deviation of e mm & 342.6 \\
\hline Tag-0 & \multirow{2}{*}{$\begin{array}{c}\text { Estimated error e } \\
\text { at time } 529 \mathrm{~s} \\
\text { mm }\end{array}$} \\
\hline Tag-1 & 237.5 \\
\hline Tag-2 & & 240.5 \\
\hline Tag-3 & & 148.3 \\
\hline Tag-4 & & 451.3 \\
\hline Tag-5 & & 525.1 \\
\hline Tag-6 & & 516.1 \\
\hline Tag-7 & & 62.8 \\
\hline & & 311.7 \\
\hline
\end{tabular}

[5]

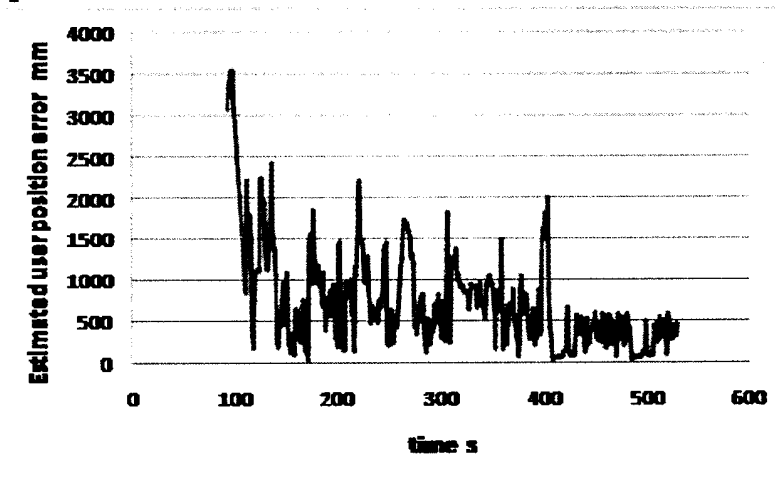

Fig.7 Estimated user position error 